Article

\title{
Organisational Skills in Academic Writing: A Study on Coherence and Cohesion in Pakistani Research Abstracts
}

\author{
Muhammad Ahmad ${ }^{1, *(\mathbb{D}}$, Muhammad Asim Mahmood ${ }^{2}$ (D) and Ali Raza Siddique ${ }^{1(D)}$ \\ 1 Department of Applied Linguistics, Government College University, Faisalabad 38000, Pakistan; \\ aalimalik381@gmail.com \\ 2 Faculty of Social Sciences, Government College University, Faisalabad 38000, Pakistan; masimrai@gmail.com \\ * Correspondence: ahmad453@yandex.com
}

Received: 11 June 2019; Accepted: 13 November 2019; Published: 17 November 2019

check for updates

\begin{abstract}
Writing requires a suitable and strategic use of language with communicative potential and structural correctness. The use of coherence and cohesion helps create communicative potential and structural correctness in texts. This study aims to investigate the use of cohesive items in the abstracts of Pakistani research articles and thereby determine what type of cohesive items are frequently used by writers. In addition, the study aims to know what functions the said writers achieve through the most frequently used cohesive items. For this purpose, 50 abstracts were retrieved from two famous Pakistani research journals (25 articles per journal), which were developed into a corpus for the study and analysed through AntConc. 3.4.4.0. The results revealed that Pakistani research writers used reference items the most frequently to achieve "directive" as well as "referential" functions. On the basis of these findings, the study concluded that Pakistani research article writers organised information in abstracts using reference items the most frequently and they were mainly concerned with directive as well as referential functions of meaning. The results also showed that the said writers organised texts on a syntactic level only, which implied that they should organise texts on a semantic level also. This would be possible with the use of repetition devices.
\end{abstract}

Keywords: abstracts; academic writing; coherence and cohesion; cohesive items; organisational skills

\section{Introduction}

\subsection{Writing}

Writing requires a suitable and strategic use of language with communicative potential and structural correctness. It is for these reasons that writing is thought to be a difficult task in the L2 learning process (Hyland 2003). Kellogg (2001) regards it as a cognitive process that has the capacity to test human memory, thinking ability and oral power to convey ideas or thoughts. In fact, good writing skills mean successful L2 learning (Hyland 2003; Nickerson et al. 2014). In the last decades, writing skills, alongwith learning them, have become very significant due to two main factors: (1) the use of writing as a means to convey ideas and (2) researchers' interest in exploring problems faced by L2 writers (Graham and Perin 2007).

\subsection{Significance of the Writing ofEnglish as a Foreign/Second Language}

In an EFL/ESL teaching and learning process, writing has always been given paramount importance. Rao regards EFL writing as significant for two main reasons: (i) it triggers a thinking process, the organisation of ideas, and an ability to analyse, criticise and summarise (Rao 2007). In relation to this research, academic writing is more significant, as according to Ahmed (2010), it helps learners 
acquire essential skills to understand what they are studying and what they are expressing with their words.

\subsection{Research Aim}

This research aimed to know the following:

1. The most frequently used cohesive items in abstracts written by Pakistani research article writers;

2. The functions performed by the cohesive items in the abstracts written by Pakistani research article writers; and

3. The differences and similarities in the use of cohesive items in the abstracts written by Pakistani research article writers.

\subsection{Research Questions}

1. What are the most frequently used cohesive items in abstracts written by Pakistani research article writers? This was adopted from (Alarcon and Morales 2011; Chanyoo 2018; Liu and Braine 2005).

2. What functions do the cohesive items perform in the abstracts written by Pakistani research article writers?

\subsection{Significance of the Study}

According to estimates from Clarivate Analytics, a famous publishing company, Pakistan topped the list in terms of the percentage rise in publications in 2018 (up to 21\%), which was the highest in the world during that year (Makri 2018). A number of studies (see Ahmad et al. 2013; Ahmed 2010; Dar and Khan 2015; Fareed et al. 2016) have claimed that Pakistani English composition lacks organisational skills. There is a possibility that the articles written by Pakistani researchers might also have organisation-related problems. Therefore, this study will help add to the existing literature on the use of organisational skills in research article writing in general and in Pakistani research article writing in particular. The study is pioneering because no such study has been conducted in the context of Pakistani research article writing, and it will highlight organisational skills in the abstracts written by Pakistani research article writers and invite the researchers to explore the problems related to organisational skills in research writing. The study will also invite the interest of research article writers as well as publishers, which will result in well-organised research article writing.

\section{Literature Review}

\subsection{Cohesion and Coherence}

Cohesion means lexical as well as grammatical relations lying between different textual elements (Richards et al. 1985). Cohesion forms a semantic bond between the elements of a text and some other elements that are vital to its interpretation (Halliday and Hasan 1976). It works like glue holding the text together and making the difference between the unified and un-unified sets of sentences. These bonds or relations involve intersentence or intrasentence relations as well as structural and lexical interdependency. It is not only semantic but also syntactic in nature (Kuo 1995). Different cohesive devices, e.g., conjunctions, ellipses, references, and substitutions, help create the said relations or bonds in the texts (Halliday and Hasan 1976). On the contrary, coherence refers to relations based on theme, communicative purpose, and the organisation of information (Kuo 1995). Coherence, in simple words, refers to the sense relations among single textual units, i.e., propositions or sentences. It makes the texts semantically as well as logically consistent for readers or hearers.

\subsection{Differences between Cohesion and Coherence}

Text linguistics is concerned with the marking of a difference between "cohesion" and "coherence" (De Beaugrande and Dressler 1981; Halliday 1994). Halliday (1994) differentiated between cohesion 
and coherence in terms of external and internal relations found in a clause. Cohesion forms the structure of a text, whereas coherence structures the clause message of a text. Brinker (2005) has stressed that the structure of a text can be analysed on grammatical as well as thematic levels, i.e., in terms of semantic-syntactic relations between logic semantics and sentence (cohesion) relations set between propositions that form thematic structures.

The notion of a functional relationship between cohesion and coherence has led to much debate discussing whether cohesion is a sufficient criterion for textual coherence or not (see Brinker 2005; Brown et al. 1983; Halliday and Hasan 1976; Halliday 1994; Hellman 1995). In many cases, coherence has been regarded as subject to, or preconditioned by, cohesion (Halliday 1994). Halliday and Hasan even maintained that cohesion is "the ONLY source of texture" (Halliday and Hasan 1976, p. 9). These views have been confronted by many researchers (see Brinker 2005; Brown et al. 1983; Hellman 1995). As a rule of thumb, a text can be coherent without being cohesive, and a reader can still identify coherence in a sequence of clauses even if the syntactic or semantic ties are missing. On the contrary, even if a text illustrates strong cohesion, and its component is interlinked by several cohesive bonds, it does not require coherence. For example:

Yesterday I met an old friend in London. In London, there are numerous public libraries. These libraries were visited by boys and girls. The boys are handsome, and they often go to public swimming pools. These swimming pools were closed for several weeks last year. A week has seven days. Seven days ago, I visited my grandparents in San José... (Brinker 2005, p. 41)

Though the above sentences are interlinked by different cohesive ties, the text reads somewhat awkwardly due to the lack of coherence. This lack arises because an overall theme underlying the whole structure is missing. Now compare, in contrast, the next set of examples:

(1) It was cold in the room. Someone had opened a window.

(2) There had been an accident. Two cars had crashed. Two cats died, but there were no human casualties (Brinker 2005, p. 42).

(3) John took a train from Paris to Istanbul. He likes spinach (Kehler 2002, p. 2).

Sentence (1) contains a slight hint of cohesion (as an exophoric reference). In sentence (2), the coherence of single sentences is even more visible. There are no cohesive relations explaining the three sentences as concurrent sense-related events explaining and specifying each other. Although the anaphoric reference pronoun in sentence (3) is a cohesive link, it does not help the reader establish any logical or semantic relation between John travelling from Paris to Istanbul and him having a preference for spinach. Kehler (2002) have suggested that any reader/hearer draws logical conclusions to find scenarios in which seemingly unrelated sentences become coherent. Thus, it is the logical reasoning faculty that allows one to infer logical relations between propositions from the common theme "the accident and its consequences" in a sentence such as sentence (3).

Establishing coherence in a text is, therefore, a complex cognitive achievement that involves far more than mere text-inherent factors (and therefore cohesion), as shown by Brown et al. (1983). Each text is a complex message system enabling communication between producer and recipient. The latter always attempts to interpret the intended meaning by making inferences: for the interpretation of a text, however, he or she resorts to both textual (co-text) and extra textual devices, such as context and background knowledge.

\subsection{Pakistani ESL Writing}

In the year 2002, the number of English language users had greatly increased in Pakistan from 2\% to $49 \%$ (Crystal 2003). The same number of English language users (i.e., 49\%) has been reported as persisting in later studies (see Brooks 2017; Dar and Khan 2015; Pinon and Haydon 2010). Yet, the writing skills of Pakistani ESL writers are very weak and substandard. Moreover, Pakistani ESL writers face many problems in learning English in general and in learning ESL writing skills 
in particular (Dar and Khan 2015). Of these problems, the main ones include problems related to the expansion of ideas, the selection of a topic, the selection of appropriate contents, writing topic sentences, syntax, alack of knowledge about rhetorical devices, poor vocabulary and coherence and organisation problems (Fareed et al. 2016). Some research publications have highlighted the causes for these reasons, e.g., incompetent teachers (Haider 2012; Mansoor 2005) and inappropriate teaching methodology (Ahmad et al. 2013; Siddiqui 2007).

\subsection{Academic Writing}

Academic writing has been an interesting area for researchers (see Anthony 1999; Bhatia 2014; Samraj 2005; Swales 1990; Tanskanen 2006). Research articles are recognized as an important genre of academic writing and are considered unique for their internal structures, i.e., their subgenres or parts. Every part of an article is organised in a specific way and is based on a particular purpose (Bhatia 2014; Dudley-Evans 1997; Swales 1990). The main parts of a research article include an abstract, an introduction, methodology, results, a discussion and a conclusion. Among these parts, the abstract, introduction and discussion have invited the interest of researchers in the past (see Anthony 1999; Bhatia 2014; Crookes 1986; Fredrickson and Swales 1994; Huckin 2001; Hyland 2000; Lewin et al. 2005; Melander et al. 1997; Samraj 2005; Swales and Najjar 1987).

The abstract is an important part of a research article. Bhatia (2014) called it "the article synopsis". Actually, it is written with a particular communicative purpose and forms a "unique macro-organisation" based on certain moves, i.e., research aims, methods, results and conclusions (Bhatia 2014; Samraj 2005). This study will examine the organisation of 50 abstracts from research articles published in noted Pakistani research journals.

Academic writing is a form of evaluation that asks a writer to show proficiency and display knowledge reflecting disciplinary skills in thinking, interpreting and presenting (Irvin 2010). Academic writing is, indeed, a set of conventions that is used in thesis writing or the paper publication process (Murray 2013). It is a type of formal writing that is completely different from creative or personal writing (Oshima and Hogue 2007). Irvin (2010) calls academic writing a literacy task and associates two significant features with it, i.e., (1) academic writing as an argument and (2) academic writing as analysis. The presentation of an argument is a characteristic feature of academic writing that is skilfully arranged to maintain the presentation of a viewpoint that "resembles a conversation between two people who may not hold the same opinions, but they both desire better understanding of the subject matter under discussion" (Irvin 2010, p. 10). Similarly, in the view of Irvin (2010), academic writing also presents an analytical explanation of the viewpoint. This type of presentation is concerned with seeking the answer to the "how and why questions" instead of the "what questions". This type of presentation results in the following activities: (a) engagement with an open question to which an answer is not known, (b) the identification of significant parts of the subject and (c) an examination of separate parts and a determination of the relationship between them.

Swales and Feak (2012) have called academic writing a well-structured product thatis caused by the consideration of certain factors, e.g., audience, flow, organisation, purpose, style and presentation. These factors, in the view of Swales and Feak (2012), are related to how, who and why questions. Moreover, academic writing requires having proper citation as well as referencing, correct punctuation and formal spelling with a fluent flow of ideas that have coherence and cohesion. In fact, coherence and cohesion create a linguistic sense in the discourse or text, help interpret the message, and negotiate the meaning present in the texts (Poudel 2018).

Keeping this in mind, many studies have been conducted in the world that have highlighted the significance of coherence and cohesion in writing. The following paragraphs review a number of studies that will help build the argument of the study, i.e., that coherence and cohesion play a significant role in the organisation of academic texts. One of these studies was conducted by Kuo (1995). He studied cohesion and coherence from the viewpoint of the writing process, focusing particularly on how explicit or surface relations add to communicative as well as interpretative purposes of texts. In this regard, 
he explored coherence and cohesion at different levels of an academic text, i.e., lexicon, the organisation of ideas or information and sentence structure. According to the lexical cohesive analysis viewpoint, as described by Kuo, such sentences are functionally more significant for the thematic development of texts. At the sentence level, grammatical sentences may contain diverse communicative value in a given text. Additionally, patterns of new as well as given information in different paragraphs with several rhetoric functions were also noticed. He suggested that learners have pragmatic competence for the purpose of information organisation.

Liu and Braine (2005) examined the usage of cohesive devices in 50 compositions written by Chinese undergraduate EFL student writers and observed that the students could use different cohesive devices in their compositions. Among these cohesive devices, lexical devices were found to be used the most among the said students, followed by the use of references and conjunctives. The quality of essay writing was also found to significantly covary with the total number of cohesive devices used by the said writers. In addition, some problems were also identified in their compositions that were concerned with the use of lexical and reference devices.

Todd et al. (2007) investigated the link between in-text tutors' comments on postgraduate essays and connectedness in discourse at a Thai university. They divided connectedness into interactional coherence, propositional coherence and cohesion, which were analysed through topical structure analysis, lexical analysis and genre analysis by Hoey (1991). As a result, text-level connectedness features and points in students' assignments, that appeared to be potentially problematic were identified and compared against tutors' comments. The findings revealed a little bit of a relationship between the tutors' comments and connectedness analyses. The nonresults, according to researchers, might have been because of the connectedness constructs, the data, the analysis methods, or the lack of a clear relationship between textual quality and tutors' comments.

Crossley and McNamara (2010) investigated the expert ratings of individual text features, including coherence, in order to examine their relation to evaluations of holistic essay quality. The results suggested that coherence was an important attribute of overall essay quality, but the experts evaluated coherence based on the absence of cohesive cues in the essays rather than their presence. The findings of this study had important implications for understanding the text and the role of coherence in writing quality.

Fareed et al. (2016) investigated the problems faced by Pakistani undergraduate ESL essay writers and the factors that affect their writing skills and suggested possible ways to improve their writing skills. In this regard, they focused on Pakistani ESL undergraduates, as well as teachers. The content was analysed through a thematic content analysis technique. Insufficient linguistic proficiency (with command over vocabulary, grammar and syntax), a lack of ideas, a reliance on L1, weak structure organization and writing anxiety emerged as the main problems of Pakistani ESL undergraduate writers. As far as the causes of these problems were concerned, the researchers enumerated a number of factors, e.g., untrained teachers (they did not receive proper training), large classrooms, ineffective teaching methods and examination systems, a lack of writing and reading practice, a lack of ideas and low motivation. Increased reading and writing practice, incidental and conscious vocabulary teaching, reforms in the examination system, trained teachers and writing competitions were suggested as remedial measures.

Chanyoo (2018) investigated the use of common cohesive devices in the writing of Thai undergraduates majoring in English with the aim of discovering the frequency of cohesive devices, the relationship between the types and frequencies of cohesive devices, and the writing quality of the said writers in light of principles determined by writing experts. The results revealed that Thai undergraduate writers made frequent use of conjunctions, ellipses, references and reiteration. In addition, the writing scores were positively correlated with the total number of cohesive devices, the total number of words and the total number of references.

The above review leads to the conclusion that good academic writing is a combination of coherent ties as well as cohesive features, which are very significant, since they create sense in the language of 
academic texts. In addition, coherence and cohesion help create organisation in academic writing and therefore are very important.

\section{Methodology}

\subsection{Model of the Study}

For the interpretation of data, this study relied on the communicative competence framework/model proposed by Canale and Swain (1980) and Canale (1983). This model, at first, was comprised of three main components related to the field of knowledge and skills: (1) grammatical, (2) sociolinguistic and (3) strategic competence. However, in a later version of the model, Canale (1983) added some elements regarding sociolinguistic competence as the fourth component, which he called "discourse competence".

In Canale and Swain (1980), grammatical competence was mainly defined in terms of Chomsky's linguistic competence, which is why some theoreticians (e.g., Savignon 1972) whose theoretical and/or empirical work on communicative competence is largely based on the model of Canale and Swain use the term "linguistic competence" for "grammatical competence". According to Canale and Swain, grammatical competence is concerned with the mastery of linguistic code (verbal or nonverbal), which includes vocabulary knowledge as well as knowledge of morphological, syntactic, semantic, phonetic and orthographic rules. This competence enables the speaker to use the knowledge and skills needed for understanding and expressing the literal meaning of utterances.

In line with Hymes's belief about the appropriateness of language use in a variety of social situations, the sociolinguistic competence in their model includes knowledge of the rules and conventions that underlie appropriate comprehension and language use in different sociolinguistic and sociocultural contexts. Canale $(1983,1984)$ described discourse competence as the mastery of rules that determine the ways in which forms and meanings are combined to achieve a meaningful unity of spoken or written texts.

The unity of a text is enabled by cohesion in form and coherence in meaning. Cohesion is achieved through the use of cohesive devices (e.g., pronouns, conjunctions, synonyms and parallel structures), which help link individual sentences and utterances to a structural whole. The means for achieving coherence, e.g., repetition, progression, consistency, and relevant ideas, enable the organisation of meaning, i.e., they establish a logical relationship between groups of utterances.

In the model of Canale and Swain, strategic competence is composed of the knowledge of verbal and nonverbal communication strategies that is recalled to compensate for breakdowns in communication due to insufficient competence in one or more components of communicative competence. These strategies include paraphrasing; repetition; the avoidance of words, structures or themes; guessing; changes in register and style; and modifications of messages. Canale (1983) pointed out that this competence could also be used to enhance the effectiveness of communication.

However, not all of the mentioned features of the said model were part of this study. The reason was that this study aimed to check organisational skills in abstracts written by Pakistani research article writers. The reason for selecting abstracts as the corpus of the study was that the other parts (i.e., the introduction, literature review, results, discussion and conclusion) were not possible for the researchers to study due to a shortage of time. Therefore, this study focused on the grammatical knowledge that Canale (1983) and Canale and Swain (1980) called grammatical competence, Bachman and Bachman and Palmer (1996) called grammatical knowledge and Okvir (2005 in Bagarić and Djigunović 2007; Borger 2014) called language competence. Organisational knowledge (in Bachman and Palmer 1996), as is evident from Figure 1, is comprised of two subparts, i.e., grammatical knowledge and textual knowledge, which have further substeps. It utilises "vocabulary" from grammatical knowledge and "cohesion" from textual knowledge. The reason for selecting the said steps and leaving the rest was that "coherence" and "cohesion" were the main concern of the study, and therefore the rest of the constituents were not relevant. 


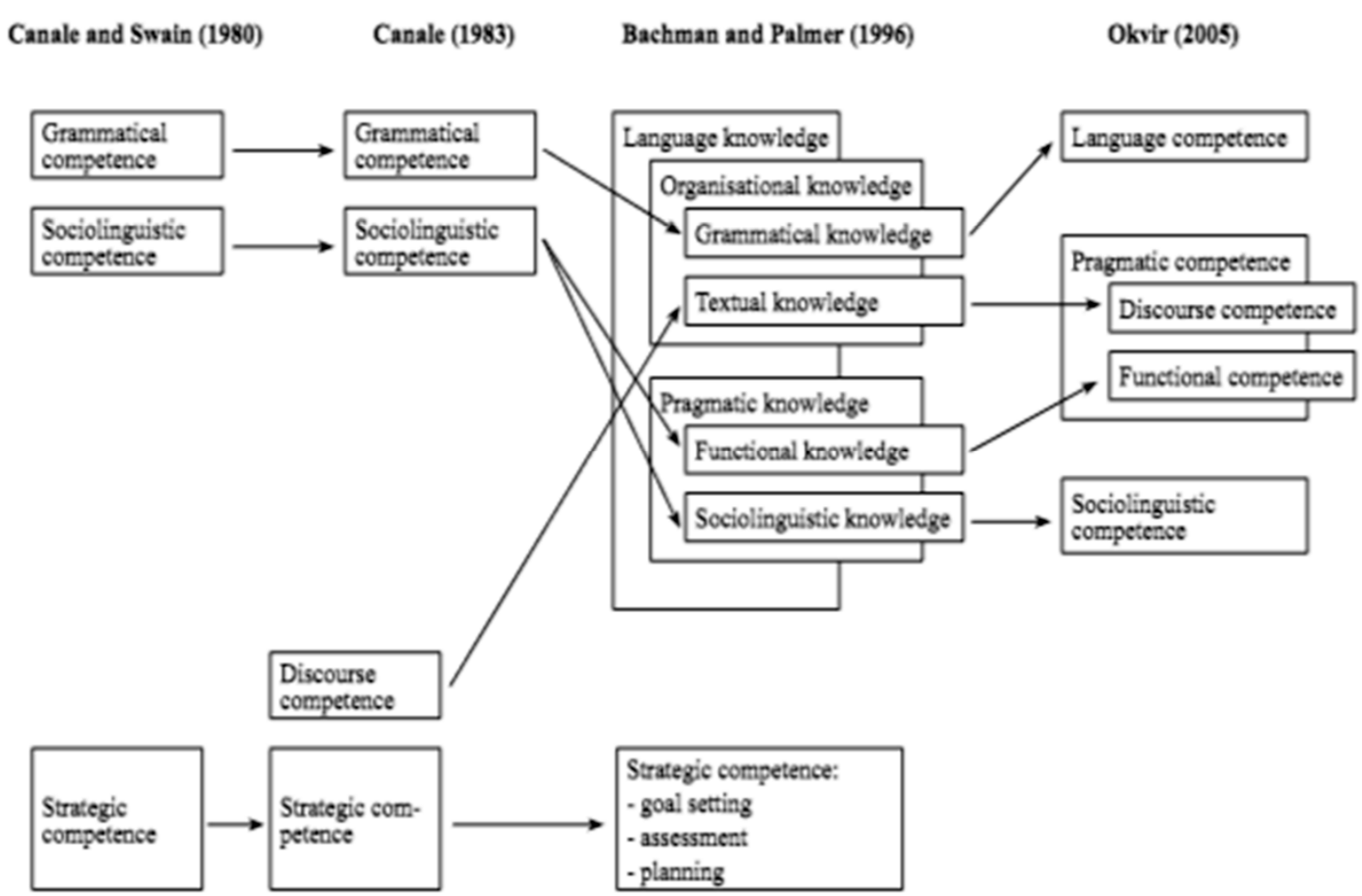

Figure 1. Similarities and differences between several models of communicative competence. Sources: Bagarić and Djigunović (2007), Borger (2014).

For divisions as well as types of cohesion, this study refers to Halliday and Hasan (1976). Halliday and Hasan (1976) think that cohesion can partly be expressed through vocabulary and partly through grammar. In this way, cohesion is of two types: (i) lexical and (ii) grammatical. The former is "the cohesive effect achieved by the selection of vocabulary" (p. 274), whereas the latter refers to a cohesive tie that is expressed through different grammatical categories (i.e., conjunctions, ellipses, references and substitutions). For details, see Table 1. The reason for utilising Halliday and Hasan (1976) model was that this was the most suitable one, offering different categories (see Tables 1 and 2) for the interpretation of the corpus of the study.

Table 1. Categories of cohesion.

\begin{tabular}{|c|c|c|c|}
\hline \multirow{11}{*}{$\begin{array}{l}\text { Categories of } \\
\text { Cohesion }\end{array}$} & \multirow{5}{*}{ Lexical Categories } & \multirow{4}{*}{ (a) } & Repetition \\
\hline & & & Synonyms \\
\hline & & & Superordinate \\
\hline & & & General words \\
\hline & & (b) & Collocation \\
\hline & \multirow{6}{*}{$\begin{array}{c}\text { Grammatical } \\
\text { Categories }\end{array}$} & \multirow{3}{*}{ (a) } & Exophoric reference (situational) \\
\hline & & & Cataphoric (follows in the text) \\
\hline & & & Anaphoric (preceded in the text) \\
\hline & & (b) & Conjunctions \\
\hline & & (c) & Ellipses \\
\hline & & (d) & Substitutions \\
\hline
\end{tabular}


Since the main concern of this study was to investigate the grammatical competence of Pakistani research article writers, we focused only on grammatical categories of cohesion (lexical categories will not be part of the analysis in this study). Grammatical categories, i.e., references, ellipses, conjunctions and substitutions, as Table 1 shows, have further subcategories (see Table 2).

This study could not investigate "ellipses" through the tools utilised for analysis. Therefore, ellipses should not be considered as part of the analysis in this study.

Table 2. Categories of grammatical cohesion.

\begin{tabular}{|c|c|c|c|}
\hline \multirow{11}{*}{$\begin{array}{l}\text { Grammatical } \\
\text { Cohesion }\end{array}$} & \multirow{4}{*}{ Reference } & Possessive & $\begin{array}{l}\text { Mine or my; yours or your; ours or our; his, } \\
\text { hers or her; its, theirs, their, its and one's }\end{array}$ \\
\hline & & Existential & $\begin{array}{l}\text { I/me, you, we/us, he/him, she/her, it, one and } \\
\text { they/them }\end{array}$ \\
\hline & & Demonstratives & $\begin{array}{l}\text { This or that, here or there, these or those and } \\
\text { definite articles(the) }\end{array}$ \\
\hline & & Comparatives & $\begin{array}{l}\text { Other, same, so many, identical, else, more, } \\
\text { similar, such, different, similarly, better }\end{array}$ \\
\hline & \multirow{3}{*}{ Substitution } & Nominal & one, ones, same \\
\hline & & \multicolumn{2}{|r|}{ Verbal } \\
\hline & & Clausal & so, not \\
\hline & \multirow{4}{*}{ Conjunctions } & Additive & $\begin{array}{l}\text { And, or, nor, and also, furthermore, or else, } \\
\text { likewise, in other words, by the way, for example, } \\
\text { thus, in addition, besides, that is, moreover, } \\
\text { likewise, similarly, in the same way, in contrast, } \\
\text { alternatively, on the other hand }\end{array}$ \\
\hline & & Adversatives & $\begin{array}{l}\text { Yet, but, though, instead, only, at last, at any rate, } \\
\text { rather, anyhow, in fact, on the contrary, in any } \\
\text { case, I mean, although, despite this, nevertheless, } \\
\text { on the other hand, however }\end{array}$ \\
\hline & & Clausal & $\begin{array}{l}\text { Consequently, then, therefore, because, } \\
\text { otherwise, it follows, apart from this, hence, } \\
\text { on this basis, for this reason, so, to this end }\end{array}$ \\
\hline & & Temporal & $\begin{array}{l}\text { After, an hour later, at once, at the same time, at } \\
\text { last, at this moment, before, before that, during, } \\
\text { finally, first, formerly, in conclusion, next, } \\
\text { next day, meanwhile, previously, second, soon, } \\
\text { to sum up, then, third, up to now, when }\end{array}$ \\
\hline
\end{tabular}

\subsection{Data Collection}

The data for this study were collected in the form of research articles from two Pakistani English language and literature journals: the Linguistics and Literature Review (coded as LLR) and the ELF Annual Research Journal (coded as ELF). Both of these journals are hosted by eminent Pakistani universities and are recognised by the Higher Education Commission (HEC) of Pakistan (except for the Linguistics and Literature Review (LLR), which is in the recognition process). Both of these journals are well reputed for quality publications in the English language following peer review norms.

The data used for this research were comprised of abstracts taken from 50 research articles selected from two research journals, i.e., ELF and LLR. ELF is published annually by the Department of English, Shah Abdul Latif University, Khairpur, Pakistan. The sample articles were selected based on recent publications. For this purpose, two of the latest volumes, i.e., 19 (2017) and 20 (2018), were selected. The former included 14 articles, whereas the latter was comprised of 12 articles. Thus, the total number of articles published in the said volumes was 26 . Since the study required 25 articles, the last article 
from Volume 19 (2017) was excluded from the sample data. Similarly, LLR is published biannually by the Department of English Language and Literature, University of Management and Technology, Lahore, Pakistan. Articles published during the years 2016 (Vol. 2, Issue 2), 2017 (Vol. 3, Issues 1 and 2), and 2018 (Vol. 4, Issues 1 and 2) were retrieved from the journal's online archive. All of the volumes, i.e., 2, 3 and 4, of the LLR published five articles in every issue numbering 25 in total.

These articles and journals were judged as being representative of the articles written by Pakistani expert researchers from the field of English linguistics and literature and as being examples of good writing with the quality of texture that results from the effective use of cohesive and coherence devices. The abstracts were included, and the other sections, such as the introduction, literature review, methodology, results, discussion and conclusion, were excluded because in all of the articles selected for this study, the abstracts were easily distinguishable and comprised data that were sufficient enough for the study. Moreover, the other sections of the research articles could have quite different statistical distributions. The number of variables that could be controlled for was limited to (i) the genre, (ii) the quality of writing and (iii) the section of the article. Since the aim of this research was to test or propose a model for measuring cohesion and coherence in the abstracts, and because the results were taken only from the abstract sections of 50 research articles published in Pakistani journals and written by Pakistani researchers, the study represented only an initial step in answering questions about organisational skills in research article writing in the field of English language and literature written by Pakistani writers.

\subsection{Size and Distribution of Data}

The amount of data and their distribution in the corpus are given in Table 3.

Table 3. Size and distribution of Pakistani English language learners'/experts'/researchers' research articles.

\begin{tabular}{cc}
\hline Name of Journal & Abstract \\
\hline Linguistics and Literature Review (LLR) & 25 \\
\hline ELF Annual Research Journal (ELF) & 25 \\
\hline Total & $\mathbf{5 0}$ \\
\hline
\end{tabular}

\subsection{Procedure for Data Collection}

The procedure for data collection involved certain steps: First of all, well-renowned Pakistani journals concerned with the publication of articles from the field of English language and literature were searched and shortlisted from different Pakistani universities' websites as well as from the Higher Education Commission (HEC) of Pakistan's recognised journals list. Second, 25 very recent research articles from each journal's archive were consciously extracted. Third, all of these research articles were initially downloaded in a pdf version. Fourth, the downloaded research articles were converted into notepad files and finally saved for data analysis. A metadata file of the selected article abstracts was maintained side by side.

\subsection{Source of Tagging and Analysis Tools}

The developed data were tagged through a parts of speech (POS) tagger. After that AntConc. 3.4.4.0software was used for analysis purposes. In this regard, certain steps were taken into consideration, such as the linguistic feature "cohesive devices" to develop a list of cohesive devices. Second, the proposed list of cohesive devices was converted into a corpus expression, which was helpful in exploring all features at once. Then, the developed corpus expression of cohesive devices was searched through AntConc. 3.4.4.0. Finally, the occurrences (as results) were recorded in the form of frequencies. Lastly, all of the recorded occurrences were functionally interpreted with respect to theoretical background, as established in the literature review. 
The reason for utilising a POS tagger is that it is software with the capability of reading linguistic texts and assigning parts of speech to each word, e.g., adjective, adverb, noun and verb (see Toutanova Kristina et al. 2003). In addition, it is also capable of reading other linguistic categories (such as the cohesive categories of this study).

\section{Results}

The results of the study, which were obtained through an AntConc analysis of a corpus developed from 50 abstracts of research articles written by Pakistani research writers from the field of English linguistics and literature, (published in eminent research journals), are presented in the Tables 4 and 5 .

\subsection{Grammatical Cohesion in ELF}

The results, given in Table 4, revealed that the writers of articles used different grammatical cohesion markers (references, substitutions, conjunctions and logical connections) at different frequencies references (676 times), substitutions (16 times), conjunctions (219 times) and logical connections (11 times). Thus, references were used at a maximum frequency and logical connections were used at a minimum frequency by the writers. See Figure 2 for graphic view of the results.

Table 4. Grammatical cohesion.

\begin{tabular}{|c|c|c|}
\hline \multicolumn{2}{|c|}{ Grammatical Cohesion } & Occurrences \\
\hline \multirow{5}{*}{ References } & Personal (possessive) & 49 \\
\hline & Personal (existential) & 63 \\
\hline & Demonstratives & 540 \\
\hline & Comparatives & 24 \\
\hline & Total & 676 \\
\hline \multirow{4}{*}{ Substitution } & Nominal & 4 \\
\hline & Verbal & 0 \\
\hline & Clausal & 12 \\
\hline & Total & 16 \\
\hline \multirow{5}{*}{ Conjunctions } & Additive & 174 \\
\hline & Adversative & 15 \\
\hline & Clausal & 8 \\
\hline & Temporal & 22 \\
\hline & TOTAL & 219 \\
\hline \multicolumn{2}{|c|}{ Grand Total } & 911 \\
\hline
\end{tabular}




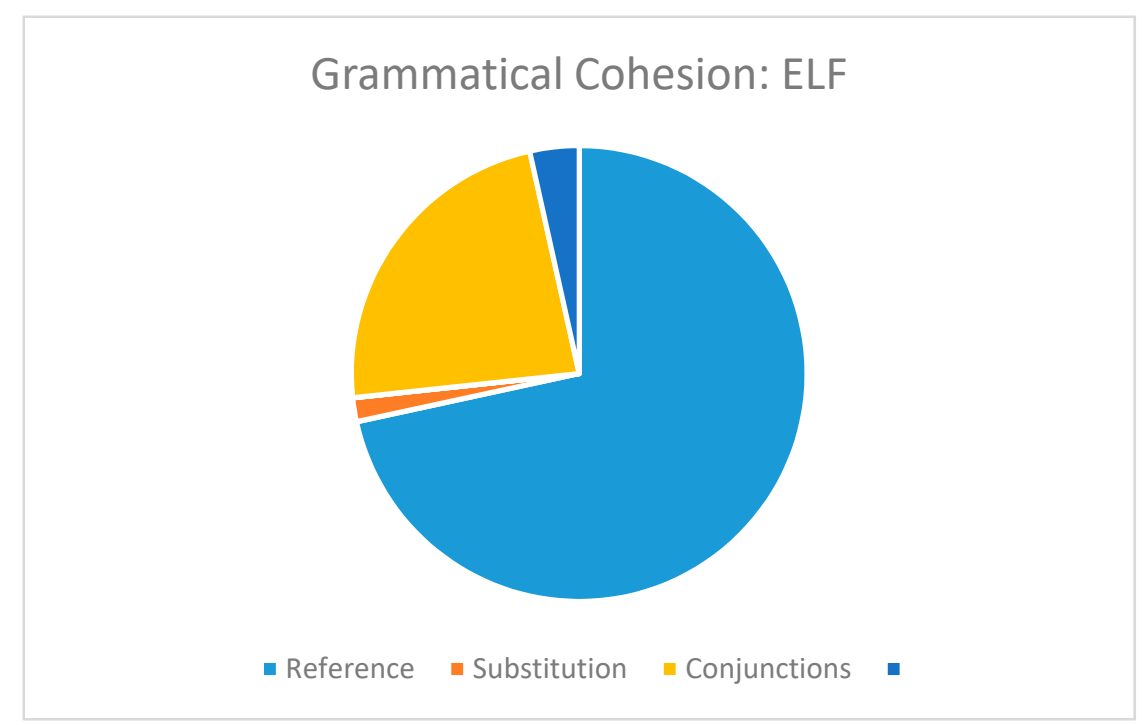

Figure 2. Cohesion in ELF.

\subsubsection{Use of Additive Conjunctions}

The writers made use of additive conjunctions in the abstracts of their articles at the highest frequency (i.e., 161 times), while the frequency of other additives (e.g., or, besides, moreover, and also and in other words) was very low: 9, 1, 1, 1 and 1 times, respectively (see Table 5).

Table 5. Additive conjunctions.

\begin{tabular}{|c|c|c|c|}
\hline Sr. No. & \multirow{7}{*}{ Conjunction } & Additive & Frequency \\
\hline 1 & & and & 161 \\
\hline 2 & & or & 9 \\
\hline 3 & & besides & 1 \\
\hline 4 & & moreover & 1 \\
\hline 5 & & and also & 1 \\
\hline 6 & & in other words & 1 \\
\hline & Total & & 174 \\
\hline
\end{tabular}

\subsubsection{Adversative Conjunctions}

In Table 6, we can see that the writers used all adversative conjunctions, but the frequencies of different adversatives (i.e., but, only, although, though) showed that the use was different. "But" was found to occur 10 times (maximum frequency), whereas the "only", "although" and "though" were found to occur 3, 1 and 1 times, respectively. Thus, the frequency of "though" and "although" was minimal.

Table 6. Adversative conjunctions.

\begin{tabular}{cccc}
\hline Sr. No. & & Adversative & Frequency \\
\cline { 1 - 1 } 1 & & but & 10 \\
\cline { 3 - 4 } 2 & \multirow{2}{*}{ Conjunction } & only & 3 \\
\cline { 3 - 4 } 3 & & although & 1 \\
\cline { 3 - 4 } 4 & & though & 1 \\
\hline & & & $\mathbf{1 5}$ \\
\hline & Total & & \\
\hline
\end{tabular}




\subsubsection{Clausal Conjunctions}

Clausal conjunctions, as is evident from Table 7, were used by the writers with low frequency.

Table 7. Clausal conjunctions.

\begin{tabular}{|c|c|c|c|}
\hline Sr. No. & \multirow{6}{*}{ Conjunction } & Clausal & Frequency \\
\hline 1 & & therefore & 3 \\
\hline 2 & & so & 2 \\
\hline 3 & & hence & 1 \\
\hline 4 & & then & 1 \\
\hline 5 & & it follows & 1 \\
\hline & Total & & 8 \\
\hline
\end{tabular}

\subsubsection{Temporal Conjunctions}

The results showed that the writers used all of the temporal conjunctions. The frequency of the use of temporal conjunctions was 22, as shown in Table 8, out of which "first" was found to occur the most (6 times). "After", "previously", "then" and "at the same time time" were found to occur the least (1 time each).

Table 8. Temporal conjunctions.

\begin{tabular}{|c|c|c|c|}
\hline Sr. No. & \multirow{10}{*}{ Conjunction } & Temporal & Frequency \\
\hline 1 & & first & 6 \\
\hline 2 & & second & 5 \\
\hline 3 & & when & 3 \\
\hline 4 & & finally & 2 \\
\hline 5 & & next & 2 \\
\hline 6 & & after & 1 \\
\hline 7 & & previously & 1 \\
\hline 8 & & then & 1 \\
\hline 9 & & at the same time & 1 \\
\hline & Total & & 22 \\
\hline
\end{tabular}

\subsubsection{Comparative Conjunctions}

The frequencies of comparative references (see Table 9) "different" and "other" (7 times each), "such" (6 times), "better" (2 times) and "same" and "similar" (1 time each) showed that the writers used all of the comparatives. "Different" and "other" were found the most, whereas, "same" and "similar" were found the least.

\subsubsection{Demonstrative References}

As far as demonstrative references (e.g., the, that, this, these, there, those, here) were concerned, the writers were found to use them in different frequencies. The demonstrative "the" was noted 437 times, which was the maximum frequency. The other demonstratives were found with much less frequency (for details, see Table 10). 
Table 9. Comparative conjunctions.

\begin{tabular}{|c|c|c|c|}
\hline Sr. No. & \multirow{7}{*}{ References } & Comparatives & Frequency \\
\hline 1 & & different & 7 \\
\hline 2 & & other & 7 \\
\hline 3 & & such & 6 \\
\hline 4 & & better & 2 \\
\hline 5 & & same & 1 \\
\hline 6 & & similar & 1 \\
\hline & Total & & 24 \\
\hline
\end{tabular}

Table 10. Demonstrative references.

\begin{tabular}{|c|c|c|c|}
\hline Sr. No. & \multirow{8}{*}{ References } & Demonstrative & Frequency \\
\hline 1 & & the & 437 \\
\hline 2 & & that & 47 \\
\hline 3 & & this & 38 \\
\hline 4 & & these & 9 \\
\hline 5 & & there & 5 \\
\hline 6 & & those & 3 \\
\hline 7 & & here & 1 \\
\hline & Total & & 540 \\
\hline
\end{tabular}

\subsubsection{Existential References}

Like other grammatical cohesion items, existential references were also used by the writers, but the use of different items was different. "It" was used the most, whereas the other references were used with much less frequency compared to the use of "it", which was at 22. In contrast "they", "her", "we", "them", "I", "one", "us", "him" and "you" were used 11, 9, 6, 4, 3, 3, 3, and 1 times, respectively. The results on the one hand, showed that the writers made use of all existential references, but on the other hand the findings showed that the writers used them with different frequencies. See Table 11 for the details.

Table 11. Existential references.

\begin{tabular}{|c|c|c|c|}
\hline Sr. No. & \multirow{11}{*}{ References } & $\begin{array}{c}\text { Personal } \\
\text { (Existential) }\end{array}$ & Frequency \\
\hline 1 & & it & 22 \\
\hline 2 & & they & 11 \\
\hline 3 & & her & 9 \\
\hline 4 & & we & 6 \\
\hline 5 & & them & 4 \\
\hline 6 & & I & 3 \\
\hline 7 & & one & 3 \\
\hline 8 & & us & 3 \\
\hline 9 & & him & 1 \\
\hline 10 & & you & 1 \\
\hline & Total & & 63 \\
\hline
\end{tabular}




\subsubsection{Possessive References}

The use of personal (possessive) references (see Table 12) in the articles published was also found to be different. The writers used "their" 31 times, "her" 9 times, "its" 7 times and "his" and "my" 1 time each.

Table 12. Possessive references.

\begin{tabular}{|c|c|c|c|}
\hline Sr. No. & \multirow{6}{*}{ References } & Personal (Possessive) & Frequency \\
\hline 1 & & their & 31 \\
\hline 2 & & her & 9 \\
\hline 3 & & its & 7 \\
\hline 4 & & his & 1 \\
\hline 5 & & my & 1 \\
\hline \multicolumn{3}{|c|}{ Total } & 49 \\
\hline
\end{tabular}

\subsubsection{Clausal Substitutions}

The findings, as shown in Table 13, indicated that Pakistani research article writers used "not" the most and "so" the least to achieve cohesion and coherence in the abstracts.

Table 13. Clausal substitutions.

\begin{tabular}{crcc}
\hline Sr. No. & & Clausal & Frequency \\
\cline { 3 - 4 } 1 & Substitution & not & 10 \\
\cline { 3 - 4 } 2 & & so & 2 \\
\hline & Total & & $\mathbf{1 2}$ \\
\hline
\end{tabular}

\subsubsection{Nominal Substitutions}

Nominal substitutions (see Table 14) were used by the writers of the articles published in the said journal to establish cohesion in the abstracts. However, nominal substitution "one" was used the most (i.e., 3) and "same" was used the least (1 time).

Table 14. Nominal substitutions.

\begin{tabular}{cccc}
\hline Sr. No. & & Nominal & Frequency \\
\cline { 3 - 4 } 1 & Substitution & one & 3 \\
\cline { 3 - 4 } 2 & & Same & 1 \\
\hline & Total & & 4 \\
\hline
\end{tabular}

\subsection{Grammatical Cohesion in the Data of the Linguistics and Literature Review Journal (LLR)}

As can be seen in Table 15, the writers of the articles published in the Linguistics and Literature Review Journal used grammatical cohesion items but with different frequencies. They used references, substitutions and conjunctions 467, 19 and 36 times, respectively. In this way, the use of references was found to be maximal, and the use of conjunctions was found to be minimal. These findings clearly indicated that the writers made maximum use of reference items and minimum use of substitutions to establish cohesion in the abstracts. For graphic view of the results, see Figure 3. 
Table 15. Grammatical cohesion.

\begin{tabular}{|c|c|c|}
\hline \multicolumn{2}{|c|}{ Grammatical Cohesion } & Occurrences \\
\hline \multirow{5}{*}{ References } & Personal (possessive) & 55 \\
\hline & Personal (existential) & 57 \\
\hline & Demonstratives & 331 \\
\hline & Comparatives & 24 \\
\hline & Total & 467 \\
\hline \multirow{4}{*}{ Substitution } & Nominal & 15 \\
\hline & Verbal & 0 \\
\hline & Clausal & 4 \\
\hline & Total & 19 \\
\hline \multirow{5}{*}{ Conjunctions } & Additive & 7 \\
\hline & Adversative & 13 \\
\hline & Clausal & 6 \\
\hline & Temporal & 10 \\
\hline & Total & 36 \\
\hline \multicolumn{2}{|c|}{ Total } & 522 \\
\hline
\end{tabular}

\section{Grammatical Cohesion: LLR}

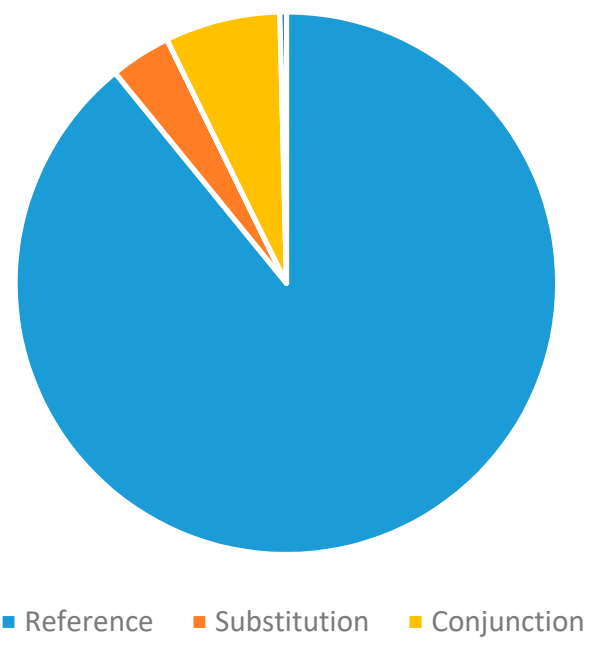

Figure 3. Grammatical cohesion.

\subsubsection{Additive Conjunctions}

The writers used all of the additive conjunctions (see Table 16) to mark cohesion in their abstracts, but the frequency of different additives was different. "Not" and "so" were found the most (2 each), and the frequencies of "in addition", "that is" and "in the same way" were found to beat a minimum (i.e., 1 each). 
Table 16. Additive conjunctions.

\begin{tabular}{cccc}
\hline Sr. No. & & Additive & Frequency \\
1 & & not & 2 \\
\cline { 3 - 3 } 2 & \multirow{3}{*}{ Conjunction } & so & 2 \\
\cline { 3 - 3 } & & in addition & 1 \\
\cline { 3 - 3 } & & that is & 1 \\
\cline { 3 - 3 } & & in the same way & 1 \\
\hline 5 & Total & & 7 \\
\hline
\end{tabular}

\subsubsection{Adversative Conjunctions}

The use of adversative conjunctions (i.e., although, but, however, instead, only, rather and though), as is evident from Table 17, was also observed at different frequencies to mark cohesion in the abstracts written by Pakistani article writers. See Table 17 for details.

Table 17. Adversative conjunctions.

\begin{tabular}{|c|c|c|c|}
\hline Sr. No. & \multirow{8}{*}{ Conjunction } & Adversative & Frequency \\
\hline 1 & & although & 3 \\
\hline 2 & & but & 3 \\
\hline 3 & & however & 3 \\
\hline 4 & & instead & 1 \\
\hline 5 & & only & 1 \\
\hline 6 & & rather & 1 \\
\hline 7 & & though & 1 \\
\hline & Total & & 13 \\
\hline
\end{tabular}

\subsubsection{Clausal Conjunctions}

The use of clausal conjunctions, e.g., so, then, hence and therefore was also noted at different frequencies in the abstracts written by Pakistani research article writers (for details, see Table 18).

Table 18. Clausal conjunctions.

\begin{tabular}{|c|c|c|c|}
\hline Sr. No. & & Clausal & Frequency \\
\hline 1 & \multirow{4}{*}{ Conjunction } & So & 2 \\
\hline 2 & & Then & 2 \\
\hline 3 & & hence & 1 \\
\hline 4 & & therefore & 1 \\
\hline & Total & & 6 \\
\hline
\end{tabular}

\subsubsection{Temporal Conjunctions}

In Table 19, it can be seen that the writers made use of different temporal conjunctions, i.e., when, first, then, after, during and finally, to mark cohesion in the abstracts (with different frequencies, i.e., 3 , 2, 2, 1, 1 and 1, respectively). 
Table 19. Temporal conjunctions.

\begin{tabular}{|c|c|c|c|}
\hline Sr. No. & \multirow{7}{*}{ Conjunction } & Temporal & Frequency \\
\hline 1 & & when & 3 \\
\hline 2 & & first & 2 \\
\hline 3 & & then & 2 \\
\hline 4 & & after & 1 \\
\hline 5 & & during & 1 \\
\hline 6 & & finally & 1 \\
\hline & Total & & 10 \\
\hline
\end{tabular}

\subsubsection{Enumerative Lexical Connections}

The results, as given in Table 20, revealed that the writers of the articles used only one enumerative lexical connection, i.e., "first" (2 times), to mark cohesiveness in the abstracts.

Table 20. Enumerative lexical connections.

\begin{tabular}{cccc}
\hline Sr. No. & \multirow{2}{*}{ Logical Connections } & Enumerative & Frequency \\
\cline { 3 - 4 } & & First & 2 \\
\hline & Total & 2 \\
\hline
\end{tabular}

4.2.6. Comparative References in the Data of the Linguistics and Literature Review Journal

Like all of the other above stated types of grammatical cohesion, comparative references were also found at different frequencies "same" (8 times), "other" (7 times), "different" and "such" (4 times each) and "better" (1 time only). For details see Table 21.

Table 21. Comparative references.

\begin{tabular}{|c|c|c|c|}
\hline Sr. No. & \multirow{6}{*}{ References } & Comparatives & Frequency \\
\hline 1 & & same & 8 \\
\hline 2 & & other & 7 \\
\hline 3 & & different & 4 \\
\hline 4 & & such & 4 \\
\hline 5 & & better & 1 \\
\hline & Total & & 24 \\
\hline
\end{tabular}

\subsubsection{Demonstrative References}

In Table 22, we can see that there was a different representation of demonstrative references in the data from the Linguistics and Literature Review Journal. Here, "the" was found 270 times, which was the maximum frequency. In comparison, other demonstratives such as "this", "that", "these" and "there" were used 32, 20, 5 and 4 times, respectively. These findings indicated that the use of the demonstrative "the" was at a maximum, and the use of "there" was at a minimum. 
Table 22. Demonstrative references.

\begin{tabular}{|c|c|c|c|}
\hline Sr. No. & \multirow{6}{*}{ References } & Demonstrative & Frequency \\
\hline 1 & & the & 270 \\
\hline 2 & & this & 32 \\
\hline 3 & & that & 20 \\
\hline 4 & & these & 5 \\
\hline 5 & & there & 4 \\
\hline & Total & & 331 \\
\hline
\end{tabular}

\subsubsection{Personal (Existential) References}

Personal (existential) references (e.g., it, her, they, them, one, I, she, we) were used with different frequencies (see Table 23) to mark cohesion in the abstracts of articles published in the journal.

Table 23. Personal (existential) references.

\begin{tabular}{|c|c|c|c|}
\hline Sr. No. & \multirow{9}{*}{ References } & Personal (Existential) & Frequency \\
\hline 1 & & it & 15 \\
\hline 2 & & her & 8 \\
\hline 3 & & them & 8 \\
\hline 4 & & they & 8 \\
\hline 5 & & one & 7 \\
\hline 6 & & $\mathrm{i}$ & 5 \\
\hline 7 & & she & 5 \\
\hline 8 & & we & 1 \\
\hline \multicolumn{3}{|c|}{ Total } & 57 \\
\hline
\end{tabular}

\subsubsection{Personal (Possessive) References}

The use of personal (possessive) references in the said journal's articles, was evident (refer to Table 24). For example, "their", "its", "her", "my", "his" and "our" were found 29, 10, 8, 4, 3 and 1 times, respectively.

Table 24. Personal (possessive) references.

\begin{tabular}{|c|c|c|c|}
\hline Sr. No. & \multirow{7}{*}{ References } & $\begin{array}{c}\text { Personal } \\
\text { (Possessive) }\end{array}$ & Frequency \\
\hline 1 & & their & 29 \\
\hline 2 & & its & 10 \\
\hline 3 & & her & 8 \\
\hline 4 & & my & 4 \\
\hline 5 & & his & 3 \\
\hline 6 & & our & 1 \\
\hline & Total & & 55 \\
\hline
\end{tabular}




\subsubsection{Clausal Substitutions}

Clausal substitutions, as is evident from Table 25, were also used to mark cohesion in the abstracts of articles published in the said journal, but with equal frequency. The writers used both of the clausal substitutions, i.e., "not" and "so" 2 times each.

Table 25. Clausal substitutions.

\begin{tabular}{crcc}
\hline Sr. No. & & Clausal & Frequency \\
\cline { 3 - 4 } 1 & \multirow{2}{nn}{ Substitution } & not & 2 \\
\cline { 3 - 4 } 2 & & so & 2 \\
\hline & Total & & 4 \\
\hline
\end{tabular}

\subsubsection{Nominal Substitutions}

The use of nominal substitutions was also the same as the other cohesive devices. The writers used these substitutions with different frequencies (see Table 26) to organize the abstracts of their articles.

Table 26. Nominal substitutions.

\begin{tabular}{|c|c|c|c|}
\hline Sr. No. & \multirow{3}{*}{ Substitution } & Nominal & Frequency \\
\hline 1 & & same & 8 \\
\hline 2 & & one & 7 \\
\hline & Total & & 15 \\
\hline
\end{tabular}

\subsection{Comparison between the Frequencies of Grammatical Cohesion in the Data of ELF and LLR}

In Table 27, we can see that there were certain similarities as well as differences in the use of grammatical cohesion markers in the articles published in the said journals. A comparison of the results showed that the use of different references, e.g., possessive, existential, demonstrative and comparatives, in the ELF Annual Research Journal's articles was 49, 63, 540 and 24 times, respectively. Meanwhile, the use of the same references in the Linguistics and Literature Review Journal was 55, 57, 331 and 24 times, respectively. The use of comparative references in both of the journals was the same, i.e., 24 , and demonstrative references were the most frequent in the said journals, i.e., 540 in the ELF Annual Research Journal and 331 in the Linguistics and Literature Review Journal.

Similarly, the use of substitution in the ELF Annual Review Journal, as shown in Table 27, was as follows: nominal substitutions were found to occur 4 times, verbal substitutions were found to occur 0 times, and clausal substitutions were found to occur 12 times. As far as use in the Linguistics and Literature Review was concerned, the frequency of nominal substitutions was 15 , the frequency of verbal substitutions was 0 and the frequency of clausal substitutions was 4 . In this way, the articles published in the ELF Annual Review Journal presented clausal substitutions, and the Linguistics and Literature Review Journal presented nominal substitutions with the most frequency. The use of nominal substitutions was at a minimum in the ELF Annual Review Journal, and the use of clausal substitutions was at a minimum in the Linguistics and Literature Review Journal. In addition, the use of verbal substitutions was found to be 0 in both of the journals' articles.

The use of conjunctions was also observed in the articles published in the said journals. Table 27 shows that the writers of the articles published in the ELF Annual Review Journal used additive conjunctions (174 times), adversative conjunctions (15 times), clausal conjunctions (8 times) and temporal conjunctions (22 times). Additive, adversative, clausal and temporal conjunctions were used 7, 13, 6 and 10 times, respectively, in the articles published in the Linguistics and Literature Review Journal. The use of additive conjunctions was at a maximum in the ELF Annual Review Journal, 
whereas the use of adversative conjunctions was at a maximum in the Linguistics and Literature Review Journal.

An overall comparison of the results, as given in Table 27, shows that the writers of the articles published in the ELF Annual Review Journal used different grammatical cohesion devices 911 times, whereas the writers of the articles published in the Linguistics and Literature Review Journal used the same devices 522 times. References were used the most by the authors of articles in both of the journals676 times in the ELF Annual Review Journal and 467 times in the Linguistics and Literature Review Journal.

As far as the other cohesive devices (e.g., substitutions and conjunctions) are concerned, the results indicated that the writers used the said devices with different frequencies (see Table 27).

Table 27. Comparison between the frequencies of grammatical cohesion in the data from the ELF Annual Research Journal and the Linguistics and Literature Review Journal.

\begin{tabular}{|c|c|c|c|}
\hline \multicolumn{2}{|c|}{ Grammatical Cohesion } & \multirow{2}{*}{$\begin{array}{c}\text { Occurrences in the ELF } \\
\text { Annual Research Journal } \\
49\end{array}$} & \multirow{2}{*}{$\begin{array}{c}\text { Occurrences in the } \\
\text { Linguistics and Literature } \\
\text { Review Journal }\end{array}$} \\
\hline \multirow{5}{*}{ References } & Personal (possessive) & & \\
\hline & Personal (existential) & 63 & 57 \\
\hline & Demonstratives & 540 & 331 \\
\hline & Comparatives & 24 & 24 \\
\hline & Total & 676 & 467 \\
\hline \multirow{4}{*}{ Substitution } & Nominal & 4 & 15 \\
\hline & Verbal & 0 & 0 \\
\hline & Clausal & 12 & 4 \\
\hline & Total & 16 & 19 \\
\hline \multirow{5}{*}{ Conjunctions } & Additive & 174 & 7 \\
\hline & Adversative & 15 & 13 \\
\hline & Clausal & 8 & 6 \\
\hline & Temporal & 22 & 10 \\
\hline & Total & 219 & 36 \\
\hline \multicolumn{2}{|c|}{ Grand Total } & 911 & 522 \\
\hline
\end{tabular}

\section{Discussion}

The first question of the study was to explore "what the most frequently used cohesive items in the abstracts of research articles written by Pakistani researchers in the field of English language and literature are". The writers used reference cohesion the most frequently (see Table 27 for details). These results align with the results of a study by Ahmad Muhammad and Mushtaq (2019). As far as the types of references were concerned, demonstrative references were found to be in more frequent use compared to the other types of the references (e.g., substitutions and conjunctions).

According to Halliday and Hasan, the term "reference" refers to specific items within a text or discourse that cannot be "interpreted semantically in their own right" but that "make reference to something else", i.e., some other item within the text or discourse, "for their interpretation" (Halliday and Hasan 1976, p. 31). These reference items, which refer to something else, are called directives and indicate that the "information is to be retrieved from elsewhere" (Halliday and Hasan 1976, p. 31). "The information to be retrieved is the referential meaning, the identity of the particular thing or class of things that is being referred to" (Halliday and Hasan 1976, p. 31). This aspect which refers to specific items within a text, (Halliday and Hasan (1976) have called these items directives as they 
identify things or classes of things that are being referred to), is frequent among Pakistani research article writers. This implies that Pakistani research article writers establish cohesion using reference items in their research articles, which further means that they organise the abstracts in their research articles by frequently using reference items.

Substitutions and conjunctions are as important as reference items. In fact, substitution is the process in which an item within a text or discourse is replaced by another (Halliday and Hasan 1976, p. 88). Substitution is a relation on a lexicogrammatical level (the level of grammar and vocabulary), i.e., "between linguistic items, such as words or phrases" (Halliday and Hasan 1976, p. 89). A substitute, in its broadest sense, can be seen as "a sort of counter which is used in place of the repetition of a particular item" (Halliday and Hasan 1976, p. 89). Similarly, conjunctions form a borderline with the field of lexical cohesion, since they also include lexical features. Unlike the other types of cohesive ties, "conjunctive elements are cohesive not in themselves but indirectly, by virtue of their specific meanings; they are not primarily devices for reaching out into the preceding (or following) text, but they express certain meanings which presuppose the presence of other components in the discourse" (Halliday and Hasan 1976, p. 226). It is not very easy to give a precise explanation of the way in which conjunctions create cohesion. They are not a type of semantic relation that points to something else in the text or discourse, nor are they a grammatical relation that implies that something was left out or replaced by something else. Conjunctions are different in the sense that they are "a specification of the way in which what is to follow is systematically connected to what has gone before" (Halliday and Hasan 1976, p. 227). They are able to relate linguistic elements to each other "that occur in succession but are not related by other, structural means" (Halliday and Hasan 1976, p. 227). Conjunctions usually structure a text or discourse in a precise way and bring the presented elements into a logical order. The above definitions and explanations of substitutions and conjunctions show that conjunctions and substitutions are also as important as reference items for the organisation of a text. As far as the use of substitutions and conjunctions by Pakistani research article writers is concerned, the results in Table 4 show that they used the said items with different frequencies to organise the information in the abstracts. FoIn the view of Halliday and Hasan (1976), different cohesive devices, e.g., conjunctions, references and substitutions, help create cohesive relations or bonds within text. Kuo (1995) adds that these bonds or relations work like glue that holds the texts together and makes the difference between the unified and un-unified sets of sentences these bonds/relations involve: intersentence or intrasentence relations as well as structural and lexical interdependency. Pakistani research writers were found to have successfully created cohesive relations with the help of cohesive items with different frequencies. The use of reference items was found to be the most frequent, the use of conjunctions was found to be the second most frequent, and similarly, the use of substitutions was found to be the third most frequent in the abstracts written by Pakistani research article writers from the field of English linguistics and literature. Therefore, it can be said that Pakistani research article writers establish cohesion using reference items more frequently than the other items, i.e., conjunctions and substitutions, and thereby organise information in the abstracts. According to Thompson (1996), references are sets of grammatical features that allow writers to point out that something is being repeated from somewhere back in the text. In the following example, "it" alludes to the same thing as "their bedroom": "They came into their bedroom. A large bed had been left in it" (Thompson 1996, p. 180). The findings suggest that Pakistani abstract writers prefer to use reference items, followed by conjunctions, while writing abstracts for their articles. Both of these items, i.e., references and conjunctions, are known for creating interclausal syntactic relationships, i.e., they refer to the previous ideas mentioned in a clause or a sentence (Chanyoo 2018). This indicates that Pakistani abstract writers are trying to organise their writing on a syntactic level only. Pakistani academic writers need to organise their texts on an interclausal semantic level also. This will be possible with the use of reiteration. According to Chanyoo (2018), reiteration is an interclausal semantic device that connects different parts of the same idea. Therefore, Pakistani academic writers should organise the abstracts of their articles on both semantic as well as syntactic levels to make them more organised. The present 
condition, as is evident from the results, indicates that the said writers are at the developmental stage of writing well-organised academic texts.

The second question of the study was raised to investigate the function of the use of cohesive items in the abstracts written by Pakistani researchers. The said writers were found to have used reference items, which in the view of Halliday and Hasan (1976) function as directives and indicate "that information is to be retrieved from elsewhere" (Halliday and Hasan 1976, p. 31). "[T] he information to be retrieved is the referential meaning, the identity of the particular thing or class of things that is being referred to" (Halliday and Hasan 1976, p. 31). For example:

1. Private news channels in Pakistan, although seemingly independent and objective, reek of hidden agenda establishing their affiliations with some particular political party through their programs (Abstract_26_Personal (Possessive) Reference);

2. In her novels, she makes language a means and tool to consolidate the identity of her nation through her syncretic linguistic strategy of appropriation and abrogation of English (Abstract_6_Personal (Possessive) Reference);

3. They were taught in a student-centered classroom environment (Abstract_6_Personal (Existential);

4. In both these texts, the major bulk of the narrative revolves around city life-how it influences individual lives and behaviour (Abstract_11_ Demonstrative);

5. Therefore, it is recommended that some modifications be made in these textbooks to improve the quality of teaching these aspects of language to L2 learners in Iranian high schools and guidance schools (Abstract_2_ Demonstrative);

6. It has been observed that different conversational strategies like turn-taking, interruption and overlapping are adopted by the participants to support or challenge the state point of view (Abstract_26_Comparative);

7. All such rules are added like other rules to the Urdu PCFG. An Urdu PCFG is thus obtained (Abstract_19_Comparative).

Pakistani research article writers are making use of these functions most frequently.

Similarly, conjunctions usually function to structure a text/discourse in a precise way and bring the presented elements into a logical order. Pakistani research article writers used these functions in their abstracts to present different elements in a logical order. Some of the examples are given below:

1. It has implications for all the teachers who have been teaching traditional and nontraditional adult learners in various universities of Pakistan in general (Abstract_3_Additive);

2. The paper uses both medical and literary discourse to provide a functional definition of blindness, as opposed to a strictly medical definition (Abstract_7_ Additive);

3. My aim is to show that language users have linguistic choices and that these choices are seldom neutral (Abstract_16__Additive);

4. It seems that, in their point of view, these pictures are harmful for the society in general, or maybe dangerous for themselves in particular (Abstract_22_ Additive);

5. Moreover, from a sociocultural perspective, the status of Pakistani women will be compared with American empowered women through critical discourse analysis (Abstract_6_ Additive);

6. In the same way, the data under examination indicate that complement Post Psareplaced at prehead position even though the tree is headed by English Ns, which require posthead placement of complement PPs (Abstract_11_ Adversative);

7. The protagonist of the selected text cultivates a social support for herself thatis rather challenging but acts as a buffer against negative outcomes (Abstract_16__Adversative);

8. Text and language are central to Sufi literature, and therefore Sufi poets use poetic language to mesmerize the hearts of people (Abstract_13_Clausal);

9. Literary texts, written by previously colonized nations, usually highlight the major characteristics of this recurrent historical phenomenon (Abstract_2_ Temporal); 
10. It becomes more challenging when the teaching-learning circumstances are also difficult (Abstract_4_Temporal).

The writers used these functions the second most frequently.

In the same way, the substitution items had the same structural functions as those they substituted for (Halliday and Hasan 1976). There were also different types of substitution: nominal substitution (replacement of a noun by "one, ones, same", verbal substitution (replacement of a verb by "do") and clausal substitution (replacement of a clause by "so, not") (Halliday and Hasan 1976, p. 90). Examples from the data of the study are given below:

1. One group was taught through the Learner-Centered Approach, and the other was taught through the Teacher-Centered Approach (Abstract_9_Nominal);

2. In the same way, the data under examination indicate that complement Post Ps are placed at a prehead position even though the tree is headed by English Ns, which require posthead placement of complement PPs (Abstract_11_ Nominal);

3. In doing so, it will introduce the reader to Waseem Anwar's critique, in the wake of postcolonial studies, of the dialogic nature of language in evaluations of race and gender (Abstract_15_Clausal);

4. Ghalib was not only an eyewitness to a great political change, but he was also a victim of it (Abstract_10_Clausal).

\section{Conclusions}

In light of the above results and discussions, this study concludes that Pakistani research article writers use reference, conjunction and substitution items to establish coherence and cohesion and thereby organise information in the abstracts of their articles. However, the use of reference items is frequent compared to the use of substitutions and conjunctions. This means that Pakistani research article writers are more concerned with the use of "directives", which indicates that the "information is to be retrieved from elsewhere". In addition, the said writers are also concerned with the use of "referential meaning", i.e., the "identity of the particular thing or class of things that is being referred to".

Conjunctions were the second most frequently used devices in the corpus of the study. Conjunctions and reference items create interclausal syntactic relations, which indicate that Pakistani abstract writers organise texts on a syntactic level only. To make their texts well organised, they need to organise their texts on aninterclausal semantic level also, which is possible with the help of reiteration devices. The results also indicated that Pakistani abstract writers are at the developmental stage of writing well-organised academic texts. For better and well-organised abstracts, they need to organise them on interclausal semantic and interclausal syntactic levels. For this purpose, they further need to focus on repetition, conjunctions, references and other devices while writing the abstracts of their articles.

This study analysed the use of cohesive devices in abstracts written by Pakistani article writers. Future researchers can study the use of coherent and cohesive devices in other parts of articles, i.e., the introduction, literature review, methodology, results, discussion and conclusion. Researchers can analyse and investigate the use of these devices individually or collectively. They can also compare the use of coherence and cohesion items between different parts of the same articles. The researchers can also compare the use of the items between Pakistani and native academic writers.

This research will prove very useful for Pakistani teachers of English, scholars, researchers and editors. It will prove useful for teachers in that it will tell them about the importance of coherence and cohesion in writing. It will be useful for scholars or researchers in that it will make them realize that coherence and cohesion are necessary for good research. Similarly, this study will also prove useful for the editors of journals in that they will start considering coherence and cohesion as important components of research writing, which will further result in coherent as well as cohesive research article writing. In addition, it will offer a new debate on coherence and cohesion in research articles. 
This study directs future researchers to investigate coherence and cohesion both in research articles, and dissertations. For this purpose, they can focus on different parts of research articles or dissertations e.g., the introduction, literature review, methodology, discussion, or conclusion. Researchers can study these parts collectively or individually. They can also study these parts to determine which parts are most coherent and cohesive.

Author Contributions: M.A. conceptualised the article, wrote and prepared the original draft. A.R.S. prepared and provided the corpus for the study and performed formal analysis using AntConc 3.4.4.0. Worthy M.A.M. supervised the article.

Funding: This research received no external funding.

Conflicts of Interest: The authors declare no conflicts of interest.

\section{References}

Abdelreheim, Hussein Maghawry Hussein. 2014. A Corpus-Based Discourse Analysis of Grammatical Cohesive Devices Used in Expository Essays Written by Emirati EFL Learners at Al Ghazali School, Abu Dhabi. Ph.D. Dissertation, The British University in Dubai (BUiD), Dubai, UAE.

Ahmad, Nasir, Farooq Nawaz Khan, and Nargis Munir. 2013. Factors affecting the learning of English at secondary school level in Khyber Pakhtunkhwa, Pakistan. International Journal of English Language and Literature Studies 2: 95-101.

Ahmad Muhammad, Syed Kazim Shah, and Muhammad Mushtaq. 2019. La cohesión en la escritura argumentativa: Un estudio de caso de escritores de ensayos Pakistaníes. Dilemas Contemporáneos: Educación, Política y Valores 6: $1-26$.

Ahmed, Abdel Hamid. 2010. Students' problems with cohesion and coherence in EFL essay writing in Egypt: Different perspectives. Literacy Information and Computer Education Journal (LICEJ) 1: 211-21. [CrossRef]

Alarcon, Josephine B., and Katrina Ninfa S. Morales. 2011. Grammatical cohesion in students argumentative essay. International Journal of English and Literature 2: 114-27.

Anthony, Laurence. 1999. Writing research article introductions in software engineering: How accurate is a standard model? IEEE Transactions on Professional Communication 42: 38-46. [CrossRef]

Bachman, Lyle F., and Adrian S. Palmer. 1996. Language Testing in Practice: Designing and Developing Useful Language Tests. Oxford: Oxford University Press.

Bagarić, Vesna, and Jelena Mihaljević Djigunović. 2007. Defining communicative competence. Metodika 8: 94-103.

Bhatia, Vijay Kumar. 2014. Analysing Genre: Language Use in Professional Settings. London and New York: Routledge.

Borger, Linda. 2014. Looking beyond Scores. A Study of Rater Orientations and Ratings of Speaking. Licentiate Thesis, Department of Education and Special Education, University of Gothenburg, Sweden. Available online: http://hdl.handle.net/2077/38158 (accessed on 14 November 2015).

Brinker, Klaus. 2005. Linguistische Text Analyse. Eine Einführung in Grundbegriffe und Methoden, 6th ed. Berlin: Erich Schmidt Verlag.

Brooks, Richard. 2017. Which Countries Have the Most English Speakers? February 17. Available online: https://k-international.com/blog/countries-with-the-most-english-speakers/ (accessed on 29 September 2019).

Brown, Gillian, Gillian D. Brown, and Yule George. 1983. Discourse Analysis. Cambridge: Cambridge University Press.

Canale, Michael. 1983. From communicative competence to communicative language pedagogy. In Language and Communication. Edited by Jack C. Richards and Richards W. Schmidt. London: Longman, pp. 2-27.

Canale, Michael. 1984. A communicative approach to language proficiency assessment in a minority setting. In Communicative Competence Approaches to Language Proficiency Assessment: Research and Application. Edited by Charlene Rivera. Clevedon: Multilingual Matters, pp. 107-22.

Canale, Michael, and Merrill Swain. 1980. Theoretical bases of communicative approaches to second language teaching and testing. Applied Linguistics 1: 1-47. [CrossRef]

Chanyoo, Natthapong. 2018. Cohesive devices and academic writing quality of Thai undergraduate students. Journal of Language Teaching and Research 9: 994-1001. [CrossRef] 
Crookes, Graham. 1986. Towards a validated analysis of scientific text structure. Applied Linguistics 7: 57-70. [CrossRef]

Crossley, Scott, and Danielle McNamara. 2010. Cohesion, coherence, and expert evaluations of writing proficiency. Proceedings of the Annual Meeting of the Cognitive Science Society 32: 984-89.

Crystal, David. 2003. English as a Global Language. Cambridge: Cambridge University Press.

Dar, Muhammad Fareed, and Imran Khan. 2015. Writing anxiety among public and private sectors Pakistani undergraduate university students. Pakistan Journal of Gender Studies 10: 121-36.

De Beaugrande, Robert-Alain, and Wolfgang U. Dressler. 1981. Introduction to Text Linguistics. London and New York: Routledge.

Dudley-Evans, Tony. 1997. Genre models for the teaching of academic writing to second language speakers: Advantages and disadvantages. In Functional Approaches to Written Text: Classroom Applications. Edited by Miller Tom. Washington, DC: United States Information Agency, pp. 150-59.

Fareed, Muhammad, Almas Ashraf, and Muhammad Bilal. 2016. ESL learners' writing skills: Problems, factors and suggestions. Journal of Education and Social Sciences 4: 81-92. [CrossRef]

Fredrickson, Kirstin M., and John M. Swales. 1994. Competition and discourse community: Introductions from Nysvenska studier. In Text and Talk in Professional Contexts: Selected Papers from the International Conference "Discourse and the Professions". Edited by Britt-Louise Gunnarsson, Per Linnel and Bengt Nordberg. Stockholm: ASLA, pp. 9-22.

Graham, Steve, and Dolores Perin. 2007. Writing next-effective strategies to improve writing of adolescents in middle and high schools. The Elementary School Journal 94: 169-81. [CrossRef]

Haider, Ghulam. 2012. An insight into difficulties faced by Pakistani student writers: Implications for teaching of writing. Journal of Educational and Social Research 2: 17-27.

Halliday, Michael Alexander Kirkwood. 1994. Spoken and written modes of meaning. In Media Texts: Authors and Readers. Edited by Graddol David and Boyd-Barrett Oliver. Clevedon, Philadelphia and Adelaide: Multilingual Matters Ltd., pp. 51-73.

Halliday, Michael Alexander Kirkwood, and Ruqaiya Hasan. 1976. Cohesion in English. London: Longman.

Hellman, Christina. 1995. The notion of coherence in discourse. In Focus and Coherence in Discourse Processing. Edited by Rickheit Gert and Habel Christopher. Berlin and New York: de Gruyter, pp. 190-202.

Hoey, Michael. 1991. Patterns of Lexis in Text. Oxford: Oxford University Press.

Huckin, Thomas. 2001. Abstracting from abstracts. In Academic Writing in Context: Implications and Applications. Edited by Hewings Martin. Birmingham: The University of Birmingham Press, pp. 93-103.

Hyland, Ken. 2000. Disciplinary Discourses: Social Interactions in Academic Writing. London: Pearson.

Hyland, Ken. 2003. Second Language Writing. Cambridge: Cambridge University Press.

Irvin, L. Lennie. 2010. What is academic writing? In Writing Spaces: Readings on Writing. Edited by Charles Lowe and Pavel Zemliansky. Indiana: Parlor Press, vol. 1, pp. 3-17.

Kehler, Andrew. 2002. Coherence, Reference, and the Theory of Grammar. Stanford: CSLI Publications.

Kellogg, Ronald T. 2001. Long-term working memory in text production. Memory \& Cognition 29: 43-52.

Kuo, Chih-Hua. 1995. Cohesion and coherence in academic writing: From lexical choice to organization. RELC Journal 26: 47-62. [CrossRef]

Lewin, Beverly, Fine Jonathan, and Young Lynne. 2005. Expository Discourse. London: A \& C Black.

Liu, Meihua, and George Braine. 2005. Cohesive features in argumentative writing produced by Chinese undergraduates. System 33: 623-36. [CrossRef]

Makri, Anita. 2018. Pakistan and Egypt had highest rises in research output in 2018. Nature. Available online: https://www.nature.com/articles/d41586-018-07841-9 (accessed on 29 September 2019). [CrossRef]

Mansoor, Sabiha. 2005. Language Planning in Higher Education: A Case Study of Pakistan. Karachi: Oxford University Press.

Melander, Bjorn, John M. Swales, and Kirstin M. Fredrickson. 1997. Journal abstracts from three academic fields in the United States and Sweden: National or disciplinary proclivities? In Intellectual Styles and Cross-Cultural Communication. Edited by Anna Duszak. Berlin: Mouton De Gruyter, pp. 251-272.

Murray, Rowena. 2013. Writing for Academic Journals. Berkshire: Open University Press.

Nickerson, Raymond S., David N. Perkins, and Edward E. Smith. 2014. The Teaching of Thinking. London and New York: Psychology Press.

Oshima, Alice, and Ann Hogue. 2007. Introduction to Academic Writing. New York: Longman. 
Pinon, Robert, and John Haydon. 2010. English Language Quantitative Indicators: Cameroon, Nigeria, Rwanda, Bangladesh and Pakistan. A Custom Report Compiled by Euromonitor International for the British Council. London: Euromonitor International Ltd.

Poudel, Ambika Prasad. 2018. Academic Writing: Coherence and Cohesion in Paragraph (Research Project). Dhankut M. Campus, Dhankuta, Nepal. Available online: https://www.researchgate.net/publication/ 322537095_Academic_Writing_Coherence_and_Cohesion_in_Paragraph (accessed on 3 November 2019).

Rao, Zhenhui. 2007. Training in brainstorming and developing writing skills. ELT Journal 61: 100-6. [CrossRef] Richards, Jack, John Platt, and Heidi Weber. 1985. Longman Dictionary of Applied Linguistics. London: Longman.

Samraj, Betty. 2005. An exploration of a genre set: Research article abstracts and introductions in two disciplines. English for Specific Purposes 24: 141-56. [CrossRef]

Savignon, Sandra J. 1972. Communicative Competence: An Experiment in Foreign Language Teaching. Philadelphia: The Centre for Curriculum Development Inc.

Siddiqui, Shahid. 2007. Rethinking Education in Pakistan: Perceptions, Practices and Possibilities. Karachi: Paramount Publishing Enterprise.

Swales, John M. 1990. Genre Analysis: English in Academic and Research Settings. Cambridge: Cambridge University Press.

Swales, John M., and Christine B. Feak. 2012. Academic Writing for Graduate Students: Essential Tasks and Skills. Michigan: Michigan University Press.

Swales, John M., and Hazem Najjar. 1987. The writing of research article introductions. Written Communication 4: 175-91. [CrossRef]

Tanskanen, Sanna-Kaisa. 2006. Collaborating towards Coherence: Lexical Cohesion in English Discourse. Amsterdam: John Benjamins Publishing, vol. 146.

Thompson, Geoff. 1996. Introducing Functional Grammar, 2nd ed. London: Hodder Education.

Todd, Richard Watson, Somreudee Khongput, and Pornapit Darasawang. 2007. Coherence, cohesion and comments on students' academic essays. Assessing Writing 12: 10-25. [CrossRef]

Toutanova Kristina, Dan Klein, Christopher D. Manning, and Yoram Singer. 2003. Feature-rich part-of-speech tagging with a cyclic dependency network. In Proceedings of the 2003 Conference of the North American Chapter of the Association for Computational Linguistics on Human Language Technology-Volume 1. Stroudsburg: Association for computational Linguistics, pp. 173-80.

Tsareva, Anastasia. 2010. Grammatical cohesion in argumentative essays by Norwegean and Russian learners. Master's Thesis, The University of Oslo, Oslo, Norway.

(C) 2019 by the authors. Licensee MDPI, Basel, Switzerland. This article is an open access article distributed under the terms and conditions of the Creative Commons Attribution (CC BY) license (http://creativecommons.org/licenses/by/4.0/). 